\title{
Familial adenomatous polyposis in China (Review)
}

\author{
JUN YANG ${ }^{1}$, QING WEI LIU ${ }^{2}$, LIANG WEN LI ${ }^{1}$, QIANG ZHI WANG ${ }^{1}$, MIN HONG $^{2}$ and JIAN DONG ${ }^{3}$ \\ Departments of ${ }^{1}$ Oncology and ${ }^{2}$ Internal Medicine-Oncology, First Affiliated Hospital of Kunming Medical University, \\ Kunming, Yunnan 650032; ${ }^{3}$ Department of Internal Medicine-Oncology, \\ Third Affiliated Hospital of Kunming Medical University, Kunming, Yunnan 650106, P.R. China
}

Received June 30, 2015; Accepted October 4, 2016

DOI: $10.3892 / \mathrm{ol} .2016 .5330$

\begin{abstract}
Familial adenomatous polyposis (FAP) is an autosomal dominant disease with a poor prognosis, and has been studied by clinicians and geneticists in China for the past three decades. It is estimated that FAP has an incidence of between 1 in 8,000 and 1 in 10,000 individuals, and accounts for $0.94 \%$ of colorectal cancer cases in China. Recent advances in the understanding of FAP suggest that the genotype of the patient may allow for early diagnosis and surveillance, and guide surgical and chemopreventive management. However, the genetic mechanisms of FAP vary between different countries. FAP in China has its own characteristics, and this may be due to ethnic and geographical genetic variation. In the present review the clinical manifestations and genetics of FAP in China are discussed, as well as the surgical strategies, chemotherapeutics and traditional Chinese medicines used in its treatment. Increased insight into the genetic and clinical features of FAP in the Chinese population may aid in the prevention and management of the disorder.
\end{abstract}

\section{Contents}

1. Introduction

2. Data collection

3. Clinical manifestations

4. Role of mutations

5. Surgical strategies

6. Chemoprevention

7. Roles of TCM

8. Conclusions

Correspondence to: Dr Jian Dong, Department of Internal Medicine-Oncology, Third Affiliated Hospital of Kunming Medical University, 519 Kunzhou Road, Kunming, Yunnan 650106, P.R. China

E-mail: youngjean@aliyun.com

Key words: familial adenomatous polyposis, clinical manifestations, genetics, surgical strategies, chemoprevention, traditional Chinese medicine

\section{Introduction}

Familial adenomatous polyposis (FAP) is an inherited disorder characterized by the development of hundreds to thousands of adenomas in the rectum and colon during the second decade of life (1-3). According to previous reports, including the Chinese cancer registry annual report (4), FAP in China has an incidence at birth of between 1 in 8,000 and 1 in 10,000 individuals; it manifests equally in males and females, and accounts for $0.94 \%$ of colorectal cancer (CRC) cases. Prevalence of FAP in China has been estimated to be 1-1.5 in every 100,000 individuals (5-8).

Researchers in China have studied FAP for $>30$ years (5-10). Clinically, patients with FAP presenting with numerous colorectal adenomas are easy to diagnose (11); however, it is desirable to screen out high-risk patients at earlier stages of development. Currently, only certain individuals presenting with typical extra-colonic manifestations, including congenital hypertrophy of the retinal pigment epithelium (CHRPE), are recognized as high-risk $(7,8,11,12)$. In 1991, Groden et al (13) observed that FAP is caused by germline mutations in the adenomatous polyposis coli (APC) gene, and subsequent research confirmed that FAP is an autosomal dominant disease (14-17). Members of families with a frequent history of FAP may be at high risk of developing the disease (15).

FAP is divided into three subtypes, including classic FAP (CFAP), attenuated FAP (AFAP) and mutY DNA glycosylase (MUTYH)-associated polyposis (MAP), each with unique genetics, clinical features and prognoses $(15,16)$. Germline mutations and large rearrangements in the APC gene are the primary causes of CFAP and AFAP (16-19), while mutations in the MUTYH gene cause MAP (20-23). Increasing numbers of pathogenic mutations have been reported to predispose patients to FAP, and recent advances in the understanding of FAP suggest that the genetics of each patient may allow for early diagnosis and surveillance, and guide surgical and chemopreventive management $(24,25)$. However, the genetics of FAP vary markedly between countries (26-33). FAP in China has its own unique characteristics, with the genotypes of patients with FAP varying between regions and ethnicities (5,34-36).

As in Western countries, the primary priority for patients with FAP in China is maintenance of a high quality of life (5). In the present review, the clinical manifestations and genetics of FAP in China are discussed, as well as the surgical strategies, chemotherapeutics and traditional Chinese medicines (TCM) 
used in its treatment. Increased insight into the genetic and clinical features of FAP in the Chinese population may aid in the prevention and management of the disorder.

\section{Data collection}

PubMed (www.ncbi.nlm.nih.gov/sites/entrez?db=PubMed) and Chinese search engines, including CNKI Data (www. cnki.net), Wanfang Data (www.wanfangdata.com.cn), SinoMed (www.sinomed.imicams.ac.cn) and Vip Information (www.cqvip.com), were used to search the literature for reference to FAP in China, using the key words: 'familial adenomatous polyposis', 'APC', 'MYH' and 'Chinese'.

The majority of data on the genetic variations of FAPin China is derived from published articles, databases and unpublished experimental research, including the UMD APC mutations database (www.umd.be/APC), APC-Database (www.LOVD. nl/APC), Zhejiang University-Adinovo Center APC Database (www.genomed.org/lovd2/home.php?select_db=APC) (37) and the APC Mutation Database (fap.taenzer.me). The MUTYH Mutation Database (www.LOVD.nl/MUTYH) was used to search for variation in the MUTYH gene.

\section{Clinical manifestations}

Colonic manifestations. It is established that there are primarily three subtypes of FAP. CFAP is the most common clinical phenotype and is characterized by the presence of numerous colorectal adenomas of differing sizes (Fig. 1), which if left untreated progress into CRC. The majority of FAP cases in China belong to this subtype (34-37). AFAP is a less severe form of FAP, characterized by the presence of $<100$ polyps and a later onset of CRC. AFAP in China has only been diagnosed as an independent subclass to CFAP in the past ten years (38-40). MAP is characterized by multiple adenomatous polyps, with the majority of patients with MAP presenting with fewer polyps compared with patients with CFAP. MAP is reported to be the least common subtype, accounting for 1-5\% of FAP cases in China. This apparent decreased prevalence in MAP may be due to poor recognition and detection of MAP (41-44).

Extra-colonic manifestations. Individuals with FAP are reported to develop a variety of extra-colonic gastrointestinal manifestations $(45,46)$. However, fundic gland polyps in the stomach, adenomatous polyps in the duodenum and periampullary region, and cancerization of upper gastrointestinal adenomas is rare in Chinese patients with FAP, particularly in those with CFAP (47). In 2015, Yan et al (48) reported a case of acute cholangitis due to adenomas of the CBD in a patient with FAP, accompanied by adenomatous changes in the stomach, duodenum and the ampulla of Vater.

Extra-intestinal manifestations of FAP consist mainly of cutaneous lesions, including fibromas, lipomas, and sebaceous and epidermoid cysts $(49,50)$. There are specific FAP-associated syndromes reported in China, including Gardner syndrome and Turcot syndrome (51). CHRPE is another characteristic extra-intestinal manifestation in patients with FAP (52). In 1995, Li et al (53) initially reported CHRPE in 6 patients with CFAP, and in 2010, Ding et al (54) detected CHRPE in
22 patients with FAP, suggesting that CHRPE is an indicator of patients at a high risk of FAP.

\section{Role of mutations}

Mutation analysis of the APC gene. The Leiden Open Variation Database reported $>1600$ different pathogenic APC mutations (www.chromium.lovd.nl/LOVD2/colon_cancer/home. php?select_db=APC). A total of 275 of these mutations were reported in China, 194 of which are unique to China (37). The majority of mutations are nonsense mutations or small insertions and deletions, which lead to a truncated APC protein. Mutations causing FAP in China have been reported to occur mainly in three regions of the APC gene: At the 5 ' end, prior to codon 500; near codon 1309 in the largest exon 16; or at the 3' end, following codon 1580 (37).

The mutation cluster region (MCR) in the APC gene in Western countries has been established to be localized between codons 1250 and 1464 (55,56). However, among the Chinese population, the MCR in the APC gene is not consistent with Western countries, instead localizing to exon 16, between codon 849 and 1376 (Fig. 1). According to the Chinese APC database: The 5 bp deletion, c.3927_3931delAAAGA, at codon 1309 was reported on eight occasions; the nonsense substitution, c. $3925 \mathrm{G}>\mathrm{T}$, at codon 1309 was reported on two occasions; the 2 bp deletion, c.3182_3183delAA was reported once; the $5 \mathrm{bp}$ deletion, c.3181_3185delAAACA, at codon 1061 was reported once; and the 5 bp deletion, c.3183_3187delACAAA, at codon 1061 was reported on three occasions (37). The aforementioned data indicate that the APC gene is frequently mutated between codons 1309 and 1061 in Chinese families with FAP, which is consistent with Western families (57). Furthermore, the substitution, c. $4479 \mathrm{G}>\mathrm{A}$, at codon 1493 was reported on five occasions; the 2 bp deletion, c.4393_4394delAG, at codon 1465 was reported on four occasions; the nonsense substitution, c.4012C $>\mathrm{T}$, at codon 1338 was reported on four occasions; and the nonsense substitution, c.994C $>\mathrm{T}$, at codon 332 was reported on four occasions. The data suggest that the APC gene may frequently contain polymorphisms at these points in Chinese patients with FAP (37).

Certain rare mutations of the APC gene have been reported in Chinese patients with FAP, including intron or promoter point mutations. For example, the following mutations have been detected in Chinese patients with FAP $(58,59)$ : The nonsense substitution, c. $220+40 \mathrm{~T}>\mathrm{C}$, at intron $2+39$; the nonsense substitution, c. $645+32 \mathrm{C}>\mathrm{T}$, at intron $5+32$; the 1 bp deletion, c.645+46delG, at intron 5+46. Furthermore, the nonsense substitutions, c. $1556 \mathrm{C}>\mathrm{G}$ and c.1753G $>\mathrm{A}$, have been reported at the $3^{\prime}$ untranslated region of the APC gene. However, the pathogenicity of these mutations remains unclear.

MUTYH mutation screening. There is no specialized website or database devoted to mutations in the MUTYH gene in China, as the majority of MUTYH gene screening is conducted sporadically in patients with CRC and few of these screenings were performed in Chinese patients with MAP. In 2008, Tong et al (43) identified three single nucleotide polymorphisms (SNPs) of the MUTYH gene, including IVS1-5A $>C$, IVS6+35A $>\mathrm{G}$ and c.G972C (Q335H). The SNP IVS1-5A $>$ C was confirmed to be significant in the etiopathogenesis of 


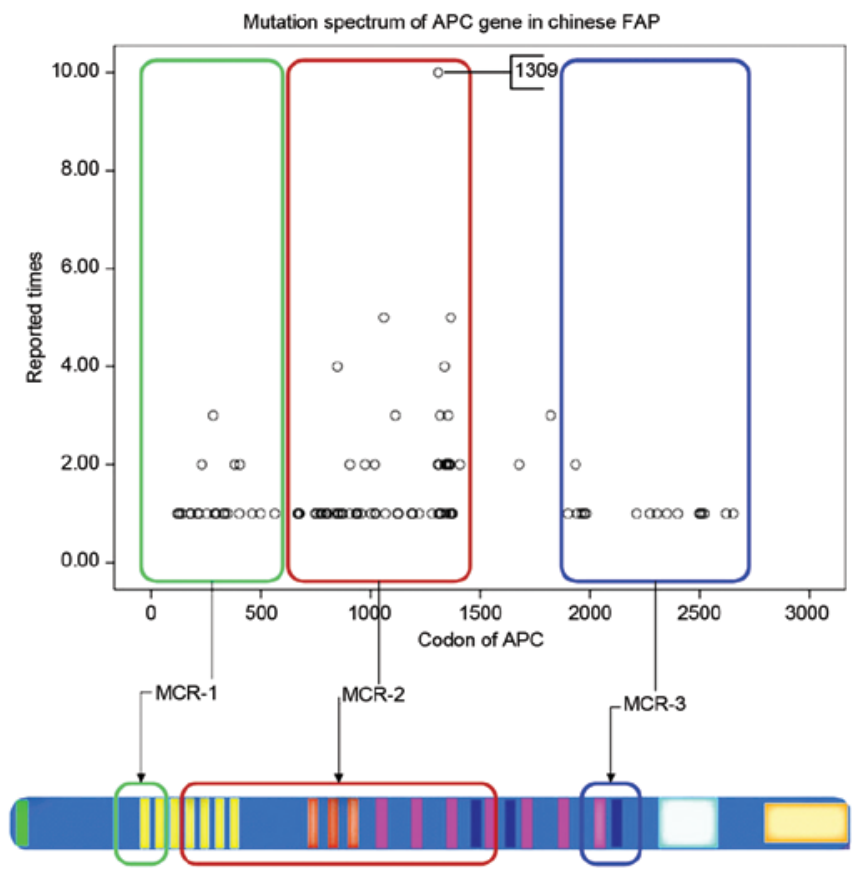

Figure 1. Mutation spectrum of the APC gene in FAP in the Chinese population. MCR-1, APC mutation variants identified at the 5' end (before codon 500). MCR-2, APC mutation variants identified between codon 849 and 1376. MCR-3, APC mutation variants identified at the 3 ' end (after codon 1580). APC, adenomatous polyposis coli; FAP, familial adenomatous polyposis; MCR, mutation cluster region.

CRC, and may be used in screening of high-risk patients (43). Currently, p.Y165C and p.G382D mutations in the MUTYH protein have only been observed in patients from Western countries $(60,61)$ and there is no identified polymorphism in the MUTYH gene for MAP patients in China.

Conventional screening techniques fail to identify $\sim 30 \%$ of families with CFAP and $\sim 90 \%$ of families with AFAP. A large subset of families with history of FAP have undetectable pathogenic changes defined as APC(-) and MUTYH(-) FAP $(62,63)$. No other specific genes predisposing an individual to FAP have been identified in China (41).

\section{Surgical strategies}

Surgical intervention is the most effective therapy for patients with FAP who present with colonic disorders, and prophylactic removal of the tumorigenic colon is considered to be the standard treatment for FAP $(64,65)$. The surgical strategies and optimal time of intervention vary between each FAP subtype (64-66). In China, patients with CFAP and advanced AFAP may be treated by total proctocolectomy with ileostomy, subtotal colectomy with ileorectal anastomosis (IRA), total colectomy or proctocolectomy with ileo-anal pouch anastomosis (IPAA), total colectomy or proctocolectomy with IPAA, subtotal colectomy plus rectal mucosectomy, IPAA through the muscular sheath of the rectum, IPAA alone and subtotal proctocolectomy $(66,67)$. IPAA offers the best available prophylaxis in CFAP patients and remains the primary alternative to IRA (66). Furthermore, laparoscopic IPAA surgery is performed in Chinese patients with FAP, and is considered to be safe, feasible and effective (68).
Patients with early stage AFAP and MAP have increased available treatment options compared with patients with CFAP and advanced AFAP $(69,70)$. Due to rapid progress in colonoscopy, doctors in China are able to remove numerous adenomas using endoscopic polyp electrocision and endoanal mucosal stripping (69). In 2006, He et al (71) reported the excision of 256 polyps in a single patient with FAP.

\section{Chemoprevention}

In order to delay the development of adenomas into adenocarcinoma and to prevent the recurrence of adenomas in the retained rectum of patients with FAP following surgical intervention, multiple drugs and dietary supplements have been identified as potential chemopreventatives $(72,73)$. The nonsteroidal anti-inflammatory drug (NSAID) sulindac $(74,75)$ and selective cyclooxygenase-2 (COX-2) inhibitor celecoxib $(76,77)$ are the typical drugs administered to control and reduce polyposis in the retained rectum following surgery. However, gastrointestinal toxicity has been observed following long-term treatment with non-selective NSAIDs (78), leading to an increase in the use of COX-2 inhibitors as the primary chemopreventive agent for patients with FAP $(79,80)$. Treatment with celecoxib alone or combined with endoscopy has proven to be effective in reducing the number of adenomas in Chinese patients with FAP $(81,82)$.

\section{Roles of TCM}

For Chinese patients with FAP who do not consent to surgical intervention or chemotherapy, TCM is an available option. In 1995, An et al (83) reported that 15 patients diagnosed with CFAP receiving TCM through oral administration and retention enema exhibited a reduction in clinical CFAP symptoms, including diarrhea and hematochezia. Furthermore, Huo et al (84) reported the case of a patient with CFAP who rejected surgical treatment and who, following 3 years of regular treatment with TCM, had only a single polyp identified by endoscopic evaluation.

\section{Conclusions}

Previously, the majority of patients with FAP in China were identified in the late stages of the disease, presenting with bowel obstructions, rectal bleeding or adenocarcinomas (5). Due to the poor prognosis and genetic diversity of FAP, clinicians and geneticists in China have studied the disease for the past three decades (5-10).

According to PubMed and multiple Chinese databases, cases of FAP among the Chinese population are mainly of the subtype CFAP. The colonic manifestations of these patients are typically easy to diagnosis (11), and extra-colonic manifestations, including CHRPE, are indicators of CFAP (12). Patients presenting with fewer adenomas $(18,19)$ are now increasingly recognized as having a separate subtype of FAP, known as AFAP, and are studied separately. However, cases of MAP in China remain rare (44).

FAP is an autosomal dominant disease $(1,13)$; mutations of the APC gene are considered to be the main causes of CFAP and AFAP $(18,19)$, and mutations of the MUTYH gene are 
associated with MAP (20-23). However, the FAP genotype varies significantly between countries (26-33). FAP in China has its own characteristics; the mutation spectrum of the APC gene in China is not consistent with the mutation spectrum of FAP in Western countries (5,34-36). The MCR of APC in Chinese patients localizes to exon 16, between codons 849 and 1376, whereas the MCR of APC in Western patients is reported to localize between codons 1250 and 1464 (50-51). In addition, mutations of APC gene polymorphisms are frequently located between codons 1309 and 1061 in Chinese patients with FAP, which is consistent with polymorphisms identified in Western countries (57). Other APC polymorphisms frequently observed include, c.4393_4394delAG at codon 1465 , c.4012C $>$ T at codon 1338 and c.994C $>\mathrm{T}$ at codon 332. As reports of MAP in the Chinese population are few in number, the frequent MCR polymorphisms in the MUTYH gene remain unclear (44). Additionally, a large subset of Chinese patients with FAP have undetectable pathogenic mutations. The rate of APC(-) and MUTYH(-) in China ranges between 30 and $60 \%$ depending on the province $(62,63)$. There are 56 ethnic groups in China, and living conditions vary between provinces (85), which may affect the genetic diversity of FAP in China.

Surgical intervention and chemotherapy has been proven to benefit patients with FAP $(64,65,72,73)$. In China, laparoscopic IPAA surgery is considered the standard treatment for patients diagnosed with CFAP and advanced AFAP $(66,67)$. Due to rapid progress in colonoscopy, doctors in China are able to remove the numerous adenomas using endoscopic polyp electrocision and endoanal mucosal stripping $(69,70)$. Celecoxib is the recommended FAP chemotherapeutic used to delay the development of adenomas into adenocarcinoma and prevent the recurrence of adenomas. Furthermore, combined celecoxib treatment and endoscopy has been proven to effectively reduce the number of adenomas in patients with FAP $(81,82)$.

For Chinese patients with FAP who do not consent to surgical operation, TCM is another option and has been used in the treatment of colonic disorders (86). Having developed over thousands of years, TCM is considered to be a complete system of healthcare and includes a complex herbal therapeutic component (87). Following treatment with TCM, patients with FAP have exhibited long-term survival and reduced colorectal symptoms, which provides evidence for the use of Chinese herbal medicine in the successful prevention and treatment of FAP $(83,84)$. Researchers in China are attempting to study the active ingredients of traditional herbal therapeutics and elucidate their mechanism of action $(86,88)$. However, further randomized controlled trials on TCM are required.

In conclusion, as the understanding of genotype-phenotype correlations between FAP subtypes increases, patients diagnosed with FAP in China are gradually benefiting from improved surgical intervention, colonoscopy, chemoprevention, surveillance and TCM. However, multiple characteristics of FAP remain unclear. There is a significant number of patients diagnosed with FAP but with no identified genetic mutation, even following sophisticated genetic testing $(41,42,44)$; due to this many high-risk individuals may be misdiagnosed. There is clinical evidence to support the possibility of influencing the manifestation of FAP through chemoprevention and lifestyle changes $(72,73)$. There are certain clinical cases showing the efficacy of TCM in the treatment of FAP, however the active ingredient remains to be elucidated. Therefore, the mechanisms of FAP require further research and evaluation.

\section{Acknowledgements}

The present review was supported by the National Natural Science Foundation of China (grant no., 81160245) and the Science and Technology Planning Project of Yunnan Province, China (grant no., 2011FB160).

\section{References}

1. Gardner EJ, Burt RW and Freston JW: Gastrointestinal polyposis: Syndromes and genetic mechanisms. West J Med 132: 488-499, 1980

2. Bianch KL, Buerke CA, Bennett AE, Lopez R, Hasson H and Church JM: Fundic gland polyp dysplasia is common in familial adenomatous polyposis. Clin Gastroenterol Heptatol 6: 180-185, 2008.

3. Nugent KP and Philips RK: Rectal cancer risk in older patients with familial adenomatous polyposis and an ileorectal anastomosis: A cause for concern. Brit J Surg 79: 1204-1206, 1992.

4. Jie He and Wan-Qing Chen: Chinese cancer registry annual report. 56-59, 2012 .

5. Shu Z, Yanqin H and Ying Y: Hereditary colorectal cancer in China. Hered Cancer Clin Pract 3: 155-164, 2005.

6. Yang L, Parkin DM, Li LD, Chen YD and Bray F: Estimation and projection of the national profile of cancer mortality in China: 1991-2005. Br J Cancer 90: 2157-2166, 2004.

7. Zhang YZ, Sheng JQ, Li SR and Zhang H: Clinical phenotype and prevalence of hereditary nonpolyposis colorectal cancer syndrome in Chinese population. World J Gastroenterol 11: 1481-1488, 2005.

8. National Hereditary Colorectal Cancer Network: Screening program of Chinese hereditary colorectal cancer. Zhonghua Zhong Liu Za Zhi 26: 191-192, 2004 (In Chinese).

9. Yutang G, Lu S and Yongbin X: Cancer incidence trend in Shanghai 1972-1994. Tumor 19: 255, 1999 (In Chinese).

10. Jiao Y, Gong E, Meng G, Liu S, Wen E and Ding Y: Detection of APC gene germline mutations in familial adenomatous polyposis patients. Beijing Yi Ke Da Xue Xue Bao 28: 267-269, 1997 (In Chinese).

11. Vasen HF: Clinical diagnosis and management of hereditary colorectal cancer syndromes. J Clin Oncol 18 (21 Suppl): 81S-92S, 2000.

12. Romania A, Zakov ZN, McGannon E, Schroeder T, Heyen F and Jagelman DG: Congenital hypertrophy of the retinal pigment epithelium in familial adenomatous polyposis. Ophthalmology 96: 879-984, 1989.

13. Groden J, Thliveris A, Samowitz W, Carlson M, Gelbert L, Albertsen H, Joslyn G, Stevens J, Spirio L, Robertson M, et al: Identification and characterization of the familial adenomatous polyposis coli gene. Cell 66: 589-600, 1991.

14. Kinzler KW, Nilbert MC, Vogelstein B, Bryan TM, Levy DB, Smith KJ, Preisinger AC, Hamilton SR, Hedge P, Markham A, et al: Identification of a gene located at chromosome 5q21 that is mutated in colorectal cancers. Science 251: 1366-1370, 1991

15. Ruhswurm I, Zehetmayer M, Dejaco C, Wolf B and Karner-Hanusch J: Ophthalmic and genetic screening in pedigrees with familial adenomatous polyposis. Am J Ophthalmol 125: 680-686, 1998.

16. Half E, Bercovich D and Rozen P: Familial adenomatous polyposis. Orphanet J Rare Dis 4: 22, 2009.

17. Powell SM, Petersen GM, Krush AJ, Booker S, Jen J, Giardiello FM, Hamilton SR, Vogelstein B and Kinzler KW: Molecular diagnosis of familial adenomatous polyposis. $\mathrm{N}$ Engl J Med 329: 1982-1987, 1993.

18. Sieber OM, Lipton L, Crabtree M, Heinimann K, Fidalgo P, Phillips RK, Bisgaard ML, Orntoft TF, Aaltonen LA Hodgson SV, et al: Multiple colorectal adenomas, classic adenomatous polyposis, and germ-line mutations in $\mathrm{MYH}$. N Eng J Med 348: 791-799, 2003. 
19. Quadri M, Vetro A, Gismondi V, Marabelli M, Bertario L, Sala P, Varesco L, Zuffardi O and Ranzani GN: APC rearrangements in familial adenomatous polyposis: Heterogeneity of deletion lengths and breakpoint sequences underlies similar phenotypes. Fam Cancer 14: 41-49, 2015.

20. Ramsoekh D, van Leerdam ME, Tops CM, Dooijes D, Steyerberg EW, Kuipers EJ and Wagner A: The use of genetic testing in hereditary colorectal cancer syndromes: Genetic testing in HNPCC, (A)FAP and MAP. Clin Genet 72: 562-567, 2007.

21. Poulsen ML and Bisgaard ML: MUTYH associated polyposis (MAP). Curr Genomics 9: 420-435, 2008.

22. Venesio T, Balsamo A, D'Agostino VG and Ranzani GN: MUTYH-associated polyposis (MAP), the syndrome implicating base excision repair in inherited predisposition to colorectal tumors. Front Oncol 2: 83, 2012.

23. Sampson JR, Dolwani S, Jones S, Eccles D, Ellis A, Evans DG Frayling I, Jordan S, Maher ER, Mak T, et al: Autosomal recessive colorectal adenomatous polyposis due to inherited mutations of MYH. Lancet 362: 39-41, 2003.

24. Kennedy RD, Potter DD, Moir CR and El-Youssef M: The natural history of familial adenomatous polyposis syndrome: A 24 year review of a single center experience in screening, diagnosis, and outcomes. J Pediatr Surg 49: 82-86, 2014.

25. Kennelly RP, Gryfe R and Winter DC: Familial colorectal cancer: Patient assessment, surveillance and surgical management. Eur J Surg Oncol pii: S0748-S7983.30675-30678, 2016.

26. Torrezan GT, da Silva FC, Santos EM, Krepischi AC, Achatz MI, Aguiar S Jr, Rossi BM and Carraro DM: Mutational spectrum of the APC and MUTYH genes and genotype-phenotype correlations in Brazilian FAP, AFAP, and MAP patients. Orphanet J Rare Dis 8: 54, 2013.

27. Vandrovcová J, Stekrová J, Kebrdlová V and Kohoutová M: Molecular analysis of the APC and MYH genes in Czech families affected by FAP or multiple adenomas: 13 novel mutations. Hum Mutat 23: 397, 2004.

28. Gómez-Fernández N, Castellví-Bel S, Fernández-Rozadilla C, Balaguer F, Muñoz J, Madrigal I, Milà M, Graña B, Vega A, Castells A, et al: Molecular analysis of the APC and MUTYH genes in Galician and Catalonian FAP families: A different spectrum of mutations? BMC Med Genet 10: 57, 2009.

29. Rivera B, Gonzalez S, Sánchez-Tomé E, Blanco I, Mercadillo F, Letón R, Benítez J, Robledo M, Capellá G and Urioste M: Clinical and genetic characterization of classical forms of familial adenomatous polyposis: A Spanish population study. Ann Oncol 22: 903-909, 2011.

30. Fostira F, Thodi G, Sandaltzopoulos R, Fountzilas G and Yannoukakos D: Mutational spectrum of APC and genotype-phenotype correlations in Greek FAP patients. BMC Cancer 10: 389, 2010.

31. Kanter-Smoler G, Fritzell K, Rohlin A, Engwall Y, Hallberg B Bergman A, Meuller J, Grönberg H, Karlsson P, Björk J and Nordling M: Clinical characterization and the mutation spectrum in Swedish adenomatous polyposis families. BMC Med 6: 1-10, 2008

32. Friedl W and Aretz S: Familial adenomatous polyposis: Experience from a study of 1164 unrelated German polyposis patients. Hered Cancer Clin Pract 3: 95-114, 2005.

33. Wachsmannova-Matelova L, Stevurkova V, Adamcikova Z, Holec V and Zajac V: Polymorphisms in the adenomatous polyposis coli gene in Slovak families suspected of FAP Neuro Endocrinol Lett 30 (Suppl 1): S25-S28, 2009.

34. Liang J, Lin C, Hu F, Wang F, Zhu L, Yao X, Wang Y and Zhao Y: APC polymorphisms and the risk of colorectal neoplasia: A HuGE review and meta-analysis. Am J Epidemiol 177: 1169-1179, 2013.

35. Cai Q, Sun M, Lu H, Zhang T, Mo S, Xu Y, Cai S, Zhu X and Shi D: Clinicopathological and molecular genetic analysis in Chinese typical hereditary nonpolyposis colorectal cancer pedigrees. Zhonghua Bing Li Xue Za Zhi 30: 339-344, 2001 (In Chinese).

36. Sheng JQ, Cui WJ, Fu L, Jin P, Han Y, Li SJ, Fan RY, Li AQ, Zhang MZ and Li SR: APC gene mutations in Chinese familial adenomatous polyposis patients. World J Gastroenterol 16: 1522-1526, 2010

37. Pan M, Cong P, Wang Y, Lin C, Yuan Y, Dong J, Banerjee S, Zhang T, Chen Y, Zhang T, et al: Novel LOVD databases for hereditary breast cancer and colorectal cancer genes in the Chinese population. Hum Mutat 32: 1335-1340, 2011
38. Su F, Wang T, Zhang MF and Wang BM: The significance of APC protein expression in the Dagnosis of AFAP. Digestive Disease and Endoscopy 2: 26-30, 2008 (In Chinese)

39. Su F, Wang T and Wang BM: Attenuated familial adenomatous. Zhong Guo Xiao Hua Nei Jing 2: 20-26, 2008 (In Chinese).

40. Lou Z, Yu ED and Meng RG: Attenuated familial adenomatous polyposis. Zhong Hua Wei Chang Wai Ke Za Zhi Bian Ji Bu 9: 81-83, 2006 (In Chinese)

41. Yang J, Liu WQ, Li WL, Chen C, Zhu Z, Wang ZQ and Dong J: Detection of APC, MYH and AXIN2 mutations for screening germline mutations predisposing to familial adenomatous polyposis. Shijie Huaren Xiaohua Zazhi 23: 556-562, 2015 (In Chinese).

42. Cheng J, Wang B and Wang T: Research progress of MYH-associated polyposis. Guo Ji Xiao Hua Bing Za Zhi She 30: 103-106, 2010 (In Chinese).

43. Jing Tong and Bing-Yuan Wang: Relationship between MUTYH gene and occurrence of colorectal cancer in family clan of familial adenomatous polyposis. Shijie Huaren Xiaohua Zazhi 16: 3576-3581, 2008 (In Chinese).

44. Zhou HH: Inherited mutations of MUTYH and colorectal cancer. Zhejiang Da Xue Xue Bao Yi Xue Ban 36: 406-411, 2007 (In Chinese)

45. Griffioen G, Bus PJ, Vasen HF, Verspaget HW and Lamers CB: Extracolonic manifestations of familial adenomatous polyposis: Desmoid tumours, and upper gastrointestinal adenomas and carcinomas. Scand J Gastroenterol Suppl 225: 85-91, 1998.

46. Konsker KA: Familial adenomatous polyposis: Case report and review of extracolonic manifestations. Mt Sinai J Med 59: 85-91, 1992.

47. Bin Zhang: A case of samilial adenomatous polyposis with fundic gland polyps. Clinical Misdiagnosis \& Mistherapy 21: 54 2008 (In Chinese).

48. Yan ML, Pan JY, Bai YN, Lai ZD, Chen Z and Wang YD: Adenomas of the common bile duct in familial adenomatous polyposis. World J Gastroenterol 21: 3150-3153, 2015.

49. Zhang Hai-Zeng, Dong Shu-Xiao, Zhou Zhi-Xiang and Shao Yong-FU: Familial adenomatous polyposis related Desmoid tumors. The Practical Journal of Cancer 21: 189-194, 2006 (In Chinese).

50. Yu ED, Lou Z, Xu XD, Meng RG, Wang H, Jin GX and Fu CG: Diagnosis and therapy of familial adenomatous polyposis with desmoid tumour. Zhong Hua Pu Tong Wai Ke Za Zhi Bian Ji Bu 21: 179-181, 2006 (In Chinese).

51. Cao HL, Wang BM and Cao XC: Clinical features of Gardner syndrome and Turcot syndrome in Chinese population: An analysis of 93 cases. Shijie Huaren Xiaohua Zazhi 18: 3922-3925, 2010 (In Chinese).

52. Nusliha A, Dalpatadu U, Amarasinghe B, Chandrasinghe PC and Deen KI: Congenital hypertrophy of retinal pigment epithelium (CHRPE) in patients with familial adenomatous polyposis (FAP); a polyposis registry experience. BMC Res Notes 7: 734, 2014.

53. Run Chun Li, Jin Wang and Jian Lin: Screening value of congenital hypertrophy of the retinal pigment epithelium for familial adenomatous polyposis. Chinese Journal of Ocular Fundus Diseases 11: 1-3, 1995 (In Chinese).

54. Yan Ding, Yu Xu and Xiao-Dong Xu: Research on the fundus fluorescein angiography in congenitaI hypertrophy of the retinaI pigment epithelium in patients with familiaI adenomatous polyposis. International Journal of Ophthalmology 10: 1157-1159, 2010.

55. Friedl W, Caspari R, Sengteller M, Uhlhaas S, Lamberti C, Jungck M, Kadmon M, Wolf M, Fahnenstich J, Gebert J, et al: Can APC mutation analysis contribute to therapeutic decisions in familial adenomatous polyposis? Experience from 680 FAP families. Gut 48: 515-521, 2001.

56. Bertario L, Russo A, Sala P, Varesco L, Giarola M, Mondini P, Pierotti M, Spinelli P and Radice P; Hereditary Colorectal Tumor Registry: Multiple approach to the exploration of genotype-phenotype correlations in familial adenomatous polyposis. J Clin Oncol 21: 1698-1707, 2003.

57. Béroud C and Soussi T: APC gene: Database of germline and somatic mutations in human tumors and cell lines. Nucleic Acids Res 24: 121-124, 1996.

58. Cai SR, Zhang SZ and Zheng S: Detection of adenomatous polyposis coli gene mutations in 31 familial adenomatous polyposis families by using denaturing high performance liquid chromatography. Zhonghua Yi Xue Yi Chuan Xue Za Zhi 25: 164-167, 2008 (In Chinese). 
59. Chen J, Guo L, Peiffer DA, Zhou L, Chan OT, Bibikova M, Wickham-Garcia E, Lu SH, Zhan Q, Wang-Rodriguez J, et al: Genomic profiling of 766 cancer-related genes in archived esophageal normal and carcinoma tissues. Int J Cancer 122: 2249-2254, 2008.

60. Gismondi V, Meta M, Bonelli L, Radice P, Sala P, Bertario L, Viel A, Fornasarig M, Arrigoni A, Gentile M, et al: Prevalence of the Y165C, G382D and 1395delGGA germline mutations of the MYH gene in Italian patients with adenomatous polyposis coli and colorectal adenomas. Int J Cancer 109: 680-684, 2004.

61. Ashton KA, Meldrum CJ, McPhillips ML, Kairupan CF and Scott RJ: Frequency of the Common MYH Mutations (G382D and Y165C) in MMR Mutation Positive and Negative HNPCC Patients. Hered Cancer Clin Pract 3: 65-70, 2005.

62. Castellsagué E, González S, Guinó E, Stevens KN, Borràs E, Raymond VM, Lázaro C, Blanco I, Gruber SB and Capellá G: Allele-specific expression of APC in adenomatous polyposis families. Gastroenterology 139: 439-447.e1, 2010.

63. Renkonen ET, Nieminen P, Abdel-Rahman WM, Moisio AL, Järvelä I, Arte S, Järvinen HJ and Peltomäki P: Adenomatous polyposis families that screen APC mutation-negative by conventional methods are genetically heterogeneous. J Clin Oncol 23: 5651-5659, 2005.

64. Warrier SK and Kalady MF: Familial adenomatous polyposis: Challenges and pitfalls of surgical treatment. Clin Colon Rectal Surg 25: 83-89, 2012.

65. Leonard D, Wolthuis A, D'Hoore A, Bruyninx L, Van De Stadt J, Van Cutsem E and Kartheuser A: Different surgical strategies in the treatment of familial adenomatous polyposis: What's the role of the ileal pouch-anal anastomosis? Acta Gastroenterol Belg 74: 427-434, 2011.

66. XIE Yu-Quan, Yuan Xing-Hua, Zheng Zhao-XU and Fang YI: Meta analysis of surgical treatment of 231 cases of familial adenomatous polyposis in China. Chinese Journal of Cancer Prevention and Treatment 15: 537-540, 2008 (In Chinese).

67. Wen Y, Lu J, Zhu M, Wu Ch, Li L and Zhu W: Surgical treatment of familial adenomatous polyposis: A report of 45 cases. Zhong Hua Pu Tong Wai Ke Za Zhi Bian Ji Bu 13: 673-675, 2004 (In Chinese)

68. Zhen Si-Hu, Hou Hui-Chi, Wang Shao-Wen, LI Wei and Liu Wei: Laparoscopic total colectomy for familial adenomatous polyposis with a report of 9 cases. Journal of Regional Anatomy and Operative Surgery 22: 629-630, 2013 (In Chinese).

69. Moussata D, Napoleon B, Lepilliez V, Klich A, Ecochard R, Lapalus MG, Nancey S, Cenni JC, Ponchon T, Chayvialle JA and Saurin JC: Endoscopic treatment of severe duodenal polyposis as an alternative to surgery for patients with familial adenomatous polyposis. Gastrointest Endosc 80: 817-825, 2014.

70. Nie Y, Zhang R, Fan K and Liang H: Familial adenomatous polyposis: A report of 10 cases in 3 generations of a family and literature review. Zhonghua Nei Ke Za Zhi 53: 290-292, 2014 (In Chinese)

71. He JT, Li XL, Jiang XY, Li J, Gong LS, Zhang YD, Lu Jand Liao CX: Clinical study on familial adenomatous polyposis treated by high frequency electric cutting under endoscope. China Journal of Modern Medicine 16: 568-570, 2006 (In Chinese).

72. Cooper K, Squires H, Carroll C, Papaioannou D, Booth A, Logan RF, Maguire C, Hind D and Tappenden P: Chemoprevention of colorectal cancer: Systematic review and economic evaluation. Health Technol Assess 14: 1-206, 2010.
73. Lang $\mathrm{M}$ and Gasche $\mathrm{C}$ : Chemoprevention of colorectal cancer. Dig Dis 33: 58-67, 2015.

74. Waddell WR and Loughry RW: Sulindac for polyposis of the colon. J Surg Oncol 24: 83-87, 1983.

75. Li J, Lu Y, Gu F, An Y and Qian Y: The long-term effects of sulindac on familial adenomatous polyposis. Zhong Hua Ziao Hua Za Zhi Bian Ji Bu 25: 153-156, 2005 (In Chinese).

76. Huang K, Gutierrez LP, Bülow S, Gallinger S, Castells A, Eagle CJ and Church JM: Clinical characteristics and outcomes in familial adenomatous polyposis patients with a long-term treatment of celecoxib: A matched cohort study. Fam Cancer 10: 303-308, 2011.

77. Wang J and Luo M: Treatment of upper gastrointestinal polyps in familial adenomatous polyposis with celexib. Chin J Surg 43: 196, 2003 (In Chinese)

78. Schnitzer TJ, Burmester GR, Mysler E, Hochberg MC, Doherty M, Ehrsam E, Gitton X, Krammer G, Mellein B, Matchaba $\mathrm{P}$, et al: Comparison of lumiracoxib with naproxen and ibuprofen in the Therapeutic Arthritis Research and Gastrointestinal Event Trial (TARGET), reduction in ulcer complications: Randomised controlled trial. Lancet 364 : 665-674, 2004

79. Lynch PM, Ayers GD, Hawk E, Richmond E, Eagle C, Woloj M, Church J, Hasson H, Patterson S, Half E and Burke CA: The safety and efficacy of celecoxib in children with familial adenomatous polyposis. Am J Gastroenterol 105: 1437-1443, 2010.

80. Lynch PM, Burke CA, Phillips R, Morris JS, Slack R, Wang X, Liu J, Patterson S, Sinicrope FA, Rodriguez-Bigas MA, et al: An international randomised trial of celecoxib versus celecoxib plus difluoromethylornithine in patients with familial adenomatous polyposis. Gut 65: 286-295, 2016.

81. Cao Yong and Zheng Chang-Qing: Effects of celecoxib combined with high frequency electric cutting under endoscopy on familial adenomatous polyposis. Practical Pharmacy And Clinical Remedies 14: 209-211, 2011 (In Chinese).

82. Li SB, Tong Q, Gao YJ, Wang Q, Zhang WG and Wang XH: A clinical study of celecoxib plus RFA/high frequency electrocoagulation and electrocision in treatment of familial adenomatous polyposis. Wei Chang Bing Xue Bian Ji Bu 14: 615-617, 2009 (In Chinese).

83. An A-Yue, Zheng Li-Hua and Huang Yue: Treatment of 15 FAP patients by oral administration and retention enema of TCM. Zhong Ji Yi Kan 30: 44-45, 1995 (In Chinese).

84. Huo Qing-Ping and Kong Lin: Treatment experience of a familial adenomatous polyposis case. SH J TCM 42: 12-13, 2008 (In Chinese).

85. Jiao Kai-Shan: Analysis of spatial statistics about Chinese minority population distribution and its changes. Journal of Southwest University for Nationalities (Humanities and Social Science) 10, 26-32, 2014 (In Chinese).

86. Piao M, Cao H, He N, Yang B, Dong W, Xu M, Yan F, Zhou B and Wang B: Berberine inhibits intestinal polyps growth in Apc (min/+) mice via regulation of macrophage polarization. Evid Based Complement Alternat Med 2016: 5137505, 2016.

87. Xu J and Yang Y: Traditional Chinese medicine in the Chinese health care system. Health Policy 90: 133-139, 2009.

88. Ping B: The effects of Chinese drugs for supporting healthy energy and removing blood stasis on postoperative metastasis of gastric carcinoma and ornithine decarboxylase. J Tradit Chin Med 18: 3-6, 1998 